\title{
The Research of Replacing the Kariba Dam with Smaller Dams
}

\author{
Wenheng $\mathrm{Li}^{1, \mathrm{a}}$ \\ ${ }^{1}$ North China Electric Power University, Baoding 071000, China \\ a442708192@qq.com
}

Keywords: Kariba Dam, model, water management capacity

\begin{abstract}
The Kariba Dam on the Zambezi River is one of the largest dams in Africa.A 2015 report by the Institute of Risk Management of South Africa included a warning that the dam is in dire need of maintenance. We try to remove the Kariba Dam and replacing it with a series of ten to twenty smaller dams along the Zambezi River ${ }^{[1]}$ to solve this problem.

Faced with the emergency situation of the Kariba Dam,we have designed a solution to the water management problem in the Zambezi River basin by establishing a model. In this model, we divide the Zambezi River into three parts:the upper, middle and lower reaches. What should be calculated is the number and size of dams built in each parts.Firstly,considering that the overall water management capacity of the new dam system needs to be the same as the water management capacity of the original Kariba Dam,the exponential estimation method is adopted to calculate the dam construction cost.Then we employ the probability model to calculate the probability that the overall regulation of the Zambian River will be normal within a certain period of time,which is regarded as a safety analysis score.After that, we can make a comprehensive evaluation to providea reasonable balance between safety and costs. The number and size of dams built for each part is able to calculated finally.
\end{abstract}

\section{Introduction}

The Kariba Dam is in the Kariba Canyon which is between Zambia and Zimbabwe ${ }^{[2]}$.It was started building in 1955 and was completed in 1959.The Kariba Dam is a concrete hyperbolic arch dam which height is 128 meters and reservoir total capacity is 184 billion cubic meter.It is one of the largest reservoir storage capacity in the world.

If the Kariba Dam collapse, it will threatens the safety of South Africa which have 3.5 million people in it, especially in Republic of Malawi and República de Moçambique ${ }^{[3]}$.And it will destroy $40 \%$ of the electricity supply in this region, the dam located in downstream will be completely submerged too. The flood will pour into the another river in Zambia and will threaten Lusaka, the capital of Zambia ${ }^{[4]}$.

A number of options are available to the Zambezi River Authority (ZRA) that might address the situation. We have to remove the Kariba Dam and replacing it with a series of ten to twenty smaller dams along the Zambezi River.

\section{The model}

Due to the flows and attitudes are different in disparate part of Zambezi River, so the dams' specification which we build in upstream, midstream and downstream are different. We set the upstream, midstream and downstream as the boundary conditions, it means that all dams in upstream are same, all dams in midstream are same and all dams in downstream are same. In the meantime, we set the dam's water storage as the standard, it means that when the water storage of all the small dams is same to the original Kariba Dam's water storage, we can think that their overall water management capabilities are same ${ }^{[5]}$.

When we know the cost of building dams in upstream and the proportion between the upstream, 
midstream and downstream, we can reckon the cost of midstream and downstream by the estimating method of index. The formula is as follows:

$$
I_{2}=I_{1} \cdot\left(\frac{Q_{2}}{Q_{1}}\right)^{\sigma} \cdot f
$$

The function I2 is the cost that we should to calculate, the function I1is the cost that we have know, the function $\frac{Q_{2}}{Q_{1}}$ is the proportion of their water flow. The function $\sigma$ is the index and we determine it as 0.6 . The function $\mathrm{f}$ is the coefficient and we determine it as 1 .

We suppose the price to build a dam in upstream is T1, the price to build a dam in upstream is $\mathrm{T} 2$, the price to build a dam in upstream is $\mathrm{T} 3$, the whole cost of those new dams is T, therefore

$$
\begin{aligned}
& T_{2}=T_{1}\left(\frac{k_{2}}{k_{1}}\right)^{0.6} \\
& T_{3}=T_{1}\left(\frac{k_{3}}{k_{1}}\right)^{0.6}
\end{aligned}
$$

So the whole cost of building these new dams is

$$
T=x_{1} \cdot T_{1}+x_{2} \cdot T_{2}+x_{3} \cdot T_{3}
$$

From the damage of original Kariba Dam we can draw a conclusion that when we use these dams for a long time it will be damaged necessarily, so we need to analyze its proportion of spoilage. We suppose its proportion of spoilage is $\mathrm{n}$ and when the whole water management ability is bigger than $\frac{2}{3} \mathrm{Ni}$ it can be used properly. We suppose the proportion that these dams can be used properly in ten years is $\mathrm{P}$, and the surplus water management ability is $\mathrm{D}$, then we can calculate that

$$
D=k_{1} \cdot t \cdot x_{1}+k_{2} \cdot t \cdot x_{2}+k_{3} \cdot t \cdot x_{3}-\frac{2}{3} N i
$$

We suppose the amount of spoiled dams in upstream is $c_{1}$, the amount of spoiled dams in upstream is $c_{2}$, the amount of spoiled dams in upstream is $c_{3}$, then the spoiled water management ability is

$$
k_{1} \cdot t \cdot c_{1}+k_{2} \cdot t \cdot c_{2}+k_{3} \cdot t \cdot c_{3}
$$

We can know that

$$
k_{1} \cdot t \cdot c_{1}+k_{2} \cdot t \cdot c_{2}+k_{3} \cdot t \cdot c_{3} \leq D
$$

Because the surplus water management ability should not be too big, so we set a restriction to it as follows:

$$
0 \leq D \leq 100 t
$$

When $0 \leq D \leq k_{1} \cdot t$, we can calculate the proportion of these dams can work well in ten years is

$$
P=(1-n)^{\left(x_{1}+x_{2}+x_{3}\right)}
$$

When $k_{1} \cdot t \leq D \leq k_{2} \cdot t$, we can calculate the proportion of these dams can work well in ten years is

$$
P=(1-n)^{\left(x_{1}+x_{2}+x_{3}\right)}+(1-n)^{\left(x_{1}+x_{2}+x_{3}\right)} \cdot C_{x_{1}}^{1}
$$

From what we write above, when $\mathrm{D}$ is a definite number, we can get the proportion these dams work well as the gist to analyze the safety. We suppose the safe gist is Z, then we can calculate that

$$
Z=100 P
$$

From above we can know that the amount these dams can be damaged is two at most. 


\section{Conclusion}

We adjust the costs and security by changing $\mathrm{x} 1, \mathrm{x} 2, \mathrm{x} 3$, and t. From the previous step analysis, we can know that increasing the wealth of water management capacity $D$ will ensure that the probability of normal operation increased. In other ways, the security of the dam is increased. By the number of $\mathrm{D}$ we can calculate the number of dam, which is a non-linear relationship. We make the analysis of the image analysis.

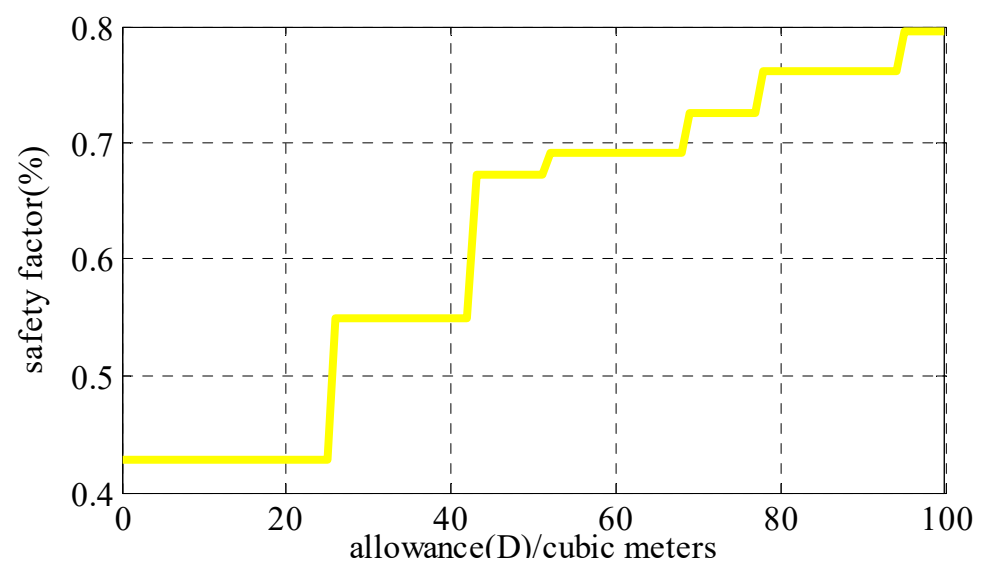

Figure 1 Capacity and safety analysis

Then we do the second step analysis, we know redundant water management ability can increase when the quantity and scale increase. Our analysis on the upstream, midstream and downstream of the dam, simply from the perspective of the number of dam impact on cost.

As you can see by the picture, to achieve the demand of water management ability.in the downstream dam cost less. Because from angle of costing, the bigger the scale of dam, the cost of the dam less when Multiple dam at the same size as a dam.

We adjust the costs and security by changing $x 1, x 2, x 3$, and t. From the previous step analysis, we can know that increasing the wealth of water management capacity $D$

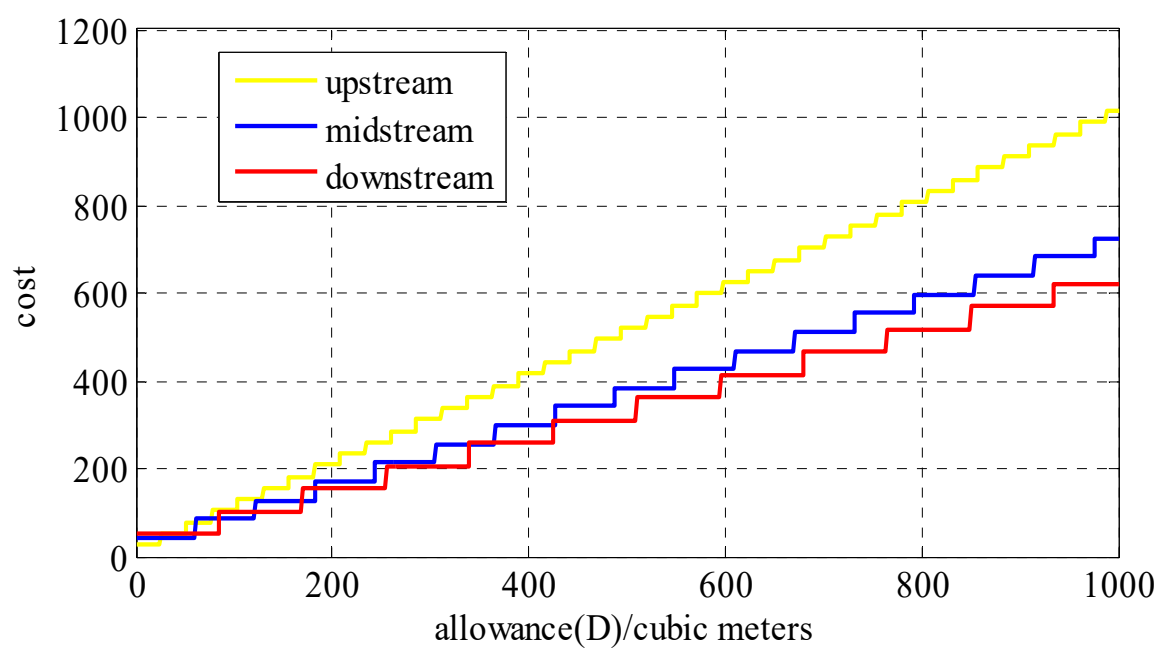

Figure 2 Cost and capacity analysis

will ensure that the probability of normal operation increased. In other ways, the security of the dam is increased. By the number of $\mathrm{D}$ we can calculate the number of dam, which is a non-linear relationship. We make the analysis of the image analysis.

Due to the model is to get the balance between cost and security, we should to judge the cost and security. We suppose the proportion of cost and security is $M$, then we can calculate that

$$
M=\frac{Z}{T}
$$


We can get the best result about this question by seek the maximum of M by MATLAB and nonlinear programming as follows:

$$
\mathrm{x}_{1}=4, \mathrm{x}_{2}=4, \mathrm{x}_{3}=3, \mathrm{~T}=0.42
$$

So the dam's unit size in upstream(the storage) is:

$$
0.42 \times 26=10.92
$$

So the dam's unit size in midstream(the storage) is:

$$
0.42 \times 61=25.62
$$

So the dam's unit size in downstream(the storage) is:

$$
0.42 \times 85=35.7
$$

The unit is 'cubic kilometers'.

From above we can know the comprehensive judgment of cost and security.

\section{References}

[1] http://www.comap.com/undergraduate/contests/

[2] http://world.people.com.cn/n/2014/0326/c157278-24743704.html

[3] http://news.xinhuanet.com/2014-03/22/c_119895202.htm

[4]"Kariba Dam". Columbia Encyclopedia, 6th Ed. Retrieved2007-07-31.

[5] International Network of Basin Organisations/Office International de L'eau: "Développer les Compétences pour mieuxGérerl'Eau: FleuvesTransfrontaliersAfricains: Bilan Global." (2002). 